\title{
Pensamento Computacional na Educação de Jovens e Adultos: desafios e oportunidades
}

\author{
Júlia dos S. B. Ortiz, Roberto Pereira
}

Programa de Pós-Graduação em Informática. Universidade Federal do Paraná - UFPR. Curitiba, Brasil.

jubathke@gmail.com, rpereira@inf.ufpr.br

\begin{abstract}
Resumo: Diferentes iniciativas para promover o desenvolvimento do pensamento computacional estão surgindo no Brasil, porém pouca atenção ainda é direcionada ao público da educação de jovens e adultos. Este é um público que busca completar a educação básica e se atualizar perante os contextos da sociedade moderna, possuindo desafios particulares de sua realidade socioeconômica. Este artigo apresenta uma discussão sobre o desenvolvimento do pensamento computacional no ensino de jovens e adultos com o intuito de sensibilizar para a importância de se investigar, propor e experimentar atividades, respeitando as particularidades deste público.
\end{abstract}

\begin{abstract}
There are different initiatives to promote the development of computational thinking in Brazil, but few of them involves students in the youth and adult education level. These students seek to complete basic education and update their knowledge, having specific needs and challenges regarding their socioeconomic conditions. This paper presents a discussion about the development of computational thinking in youth and adults education to sensitize on the importance of investigating, proposing, and experiencing activities, respecting the conditions and particularities of this public.
\end{abstract}

\section{Introdução}

O termo "computational thinking" ainda é interpretado por meio de diferentes palavras e ideias. Utilizar a computação e dispositivos tecnológicos como instrumentos para auxiliar a resolução de problemas, permitindo a expansão de habilidades mentais é uma das interpretações deste termo, de acordo com o workshop The Scope and Nature of Computational Thinking, promovido pela National Research Council (2010).

Wing (2006) argumenta que o pensamento computacional envolve a resolução de problemas, a concepção de sistemas e a compreensão do comportamento humano, baseando-se nos conceitos fundamentais da Ciência da Computação. A National Research Council (2010) diz que uma pessoa pensando computacionalmente percebe que modelos computacionais podem ajudar a resolver e entender problemas de várias áreas, como mudanças climáticas, economia, entre outros.

Recentemente, diversas iniciativas têm surgido no Brasil com o intuito de ensinar algoritmos, programação e outros fundamentos computacionais para desenvolver 
habilidades e aptidões relacionadas ao pensamento computacional. Públicos bastante visados para estas pesquisas são os alunos do próprio ensino superior em ciência da computação, alunos dos ensinos fundamental e médio, e professores.

O público da educação de jovens e adultos (EJA), entretanto, não tem sido contemplado por estas iniciativas, sendo um contexto passível de exploração e com características diferenciadas, pois possuem diversos contextos sociais, culturais e econômicos desafiadores, muitas vezes gerados pelo abandono dos estudos.

O fato de estarem retomando os estudos após a vida adulta, sugere o desejo do público da EJA de se desenvolver. Assim, o desenvolvimento do pensamento computacional nesse público poderá tanto beneficiá-los, por ser uma ferramenta capaz de ajudar na compreensão e resolução de diversos problemas, quanto trazer desafios de pesquisa, demandando a elaboração de estratégias adequadas para tal desenvolvimento.

É preciso considerar questões culturais e afetivas, de modo que esses alunos se sintam motivados a continuar aprendendo e se desenvolvendo no âmbito tecnológico, e tenham autonomia suficiente para isso, pois "não saber usar a internet em um futuro próximo será como não saber abrir um livro ou acender um fogão, não sabermos algo que nos permita viver a cidadania na sua completitude" (VAZ, 2015, p. 63).

Para se propor e experimentar formas eficientes de despertar o pensamento computacional no público de alunos da EJA e fazer com que este conhecimento tenha sentido em seus contextos, é preciso compreender a realidade sociocultural desse público. Neste artigo desenvolvemos mais essa discussão, apresentamos um mapeamento de literatura sobre as iniciativas no cenário brasileiro e apresentamos desafios e oportunidades de pesquisa neste contexto.

\section{Pensamento Computacional}

De acordo com Barr e Stephenson (2011), são habilidades do pensar computacionalmente: coleta de dados, análise de dados, representação de dados, decomposição de problemas, abstração, algoritmos e procedimentos, automação, paralelização e simulação.

Embora estas habilidades possam ser utilizadas na resolução de problemas não relacionados à computação, elas são amplamente observadas nos profissionais deste ramo, o que pode indicar que a aprendizagem das matérias relacionadas à computação, de maneira que o aluno seja capaz de saber quando, como e para que utilizá-las, pode favorecer o desenvolvimento deste modo de pensar.

O documento "Referencias de Formação em Educação" (ZORZO et al., 2017, p.7), aprovado pela Comissão de Educação, cita como habilidades relacionadas à computação e ao pensamento computacional propostas para a educação infantil: "Compreender uma situação problema criando e identificando sequências de passos de uma tarefa para sua solução."; "Representar os passos de uma tarefa através de uma 
notação pictórica, de forma organizada e relacional"; "Criar passos para solução de problemas relacionados ao movimento do corpo e trajetórias espaciais.". Para o ensino fundamental: "Representar em experiências concretas as principais abstrações para descrever dados: registros, listas e grafos."; "Identificar as principais abstrações para construir processos: escolha, composição e repetição, simulando e definindo algoritmos simples que representem situações do cotidiano infantil."; "Utilizar linguagem lúdica visual para representar algoritmos."; e "Compreender a técnica de decompor um problema para solucioná-lo.”.

Considerando as habilidades mencionadas acima, se pode perceber que, desenvolvê-las no ensino regular, significa potencializar e favorecer o aprendizado e desenvolvimento dos alunos, enquanto que para os alunos da EJA representa, além disso, uma questão de autonomia pessoal e profissional em uma sociedade permeada por tecnologias de informação e comunicação. Com a computação ubíqua se tornando realidade, será ainda mais necessário estar preparado tanto para usufruir quanto para interagir com sistemas computacionais.

\section{Educação de Jovens e Adultos}

De acordo com a lei № 9.394 de 20 de dezembro de 1996, a educação de jovens e adultos é uma oportunidade disponibilizada para aqueles que não completaram seus estudos na idade regular. Esta lei estabelece que para ingressar nesta modalidade é preciso ter idade mínima de quinze anos para o ensino fundamental e dezoito anos para o ensino médio.

De acordo com o censo escolar ${ }^{1}$, publicado no site do INEP - Instituto Nacional de Estudos e Pesquisas Educacionais Anísio Teixeira, em 2016 estavam matriculados 3.422.127 alunos nesta modalidade de ensino; e, de acordo com o IBGE - Instituto Brasileiro de Geografia e Estatística, em 2015 cerca de 15\% dos jovens entre 14 e 17 anos estavam fora das escolas, totalizando cerca de 1.600 .000 pessoas $^{2}$.

Neri $(2009$, p.5) cita que dentre os principais motivos para o abandono escolar, estão: "i) Dificuldade de acesso a escola (10,9\%); ii) Necessidade de trabalho e geração de renda (27,1\%); e iii) Falta intrínseca de interesse (40,3\%)". Estes dados indicam a existência de contextos sociais, culturais e econômicos desafiadores, que podem influenciar também no cenário de experiência com tecnologias computacionais interativas.

Nesta mesma direção, Bathke e Raabe (2016, p.10) destacam que "é preciso ter a consciência de que os adultos estão na escola por vontade própria, ninguém os exige frequência, e caso não estejam gostando das aulas, ou tenham dificuldade em algumas das atividades, levantam e vão embora sem hesitar". Além disso, Bathke e Raabe

\footnotetext{
${ }^{1}$ http://download.inep.gov.br/educacao_basica/censo_escolar/notas_estatisticas/2017/notas_estatisticas_ce nso_escolar_da_educacao_basica_2016. pdf acesso em 22/08/2017

${ }^{2}$ http://biblioteca.ibge.gov.br/visualizacao/livros/liv98965.pdf acesso em 23/08/2017
} 
VI Congresso Brasileiro de Informática na Educação (CBIE 2017)

Anais dos Workshops do VI Congresso Brasileiro de Informática na Educação (WCBIE 2017)

complementam que os alunos da EJA "já possuem uma história de vida, um trabalho, filhos, traumas, problemas, e esta situação também traz uma dificuldade em equalizar toda a turma", o que evidencia também a posse de saberes.

Sobre o exposto acima, Paulo Freire (1996) deixa claro que é dever do professor respeitar os saberes que os educandos trazem para a escola e, além disso, discutir com eles a razão de ser destes saberes. Os aspectos da comunidade e da escola também precisam ser levados em consideração. De acordo com Baranauskas e Carbajal (2017), um projeto para a inclusão de tecnologia computacional em um espaço de aprendizagem formal, como uma escola, deve ser construído com as partes que envolvem este espaço como uma organização, em seus aspectos informal, formal e técnico. Para efetivamente produzir resultados úteis e que contribuam para o público de jovens e adultos, a pesquisa nesses contextos deve estar ciente e sensibilizada para esses desafios.

\section{Mapeamento de Literatura}

Para mapear a literatura sobre iniciativas de trabalhos no cenário brasileiro, a busca foi conduzida analisando os artigos publicados no Workshop de Ensino de Pensamento Computacional, Algoritmos e Programação - WAlgProg, por ser o principal fórum atualmente dedicado ao tema no Brasil. Foram analisados todos os artigos publicados em suas primeira (2015) e segunda (2016) edições (60 artigos ao total).

Como critério de inclusão, foram considerados artigos que propõem ou relatam estratégias de ensino de conceitos da computação (algoritmos, programação, raciocínio lógico, estrutura de dados, entre outros) visando o desenvolvimento do pensamento computacional, independente do público alvo. Este critério foi estabelecido visando obter artigos que apresentem os métodos de planejamento, as técnicas, as dificuldades encontradas e demais informações que possam ser úteis na elaboração de um projeto.

A seleção preliminar foi realizada analisando: o título, o resumo e o público alvo. Um total de 40 artigos foram selecionados após a aplicação desse critério. A etapa seguinte consistiu em ler inteiramente cada artigo, a fim de verificar se o mesmo satisfaz o critério de inclusão mencionado e para se extrair seus dados.

Os artigos mapeados foram classificados nas categorias: "Nova Estratégia" trabalhos que relatam apenas a utilização de diferentes ferramentas ou estratégias para o ensino de conteúdos de computação junto aos públicos normalmente abordados (e.g., alunos da graduação de ciência da computação e cursos afins); e "Novo Público" trabalhos que, além de relatarem uso de diferentes ferramentas/estratégias, relatam também o ensino de fundamentos da computação e pensamento computacional para públicos diferenciados, como os alunos da EJA, por exemplo.

Como critérios de exclusão, foram desconsideradas as pesquisas que relatavam análise/proposta de ferramentas, análises de oportunidades e revisões sistemáticas, pois tais artigos não fazem parte do escopo da pesquisa. Ao término desta etapa, os trabalhos 
relacionados somavam 31, e foram classificados da seguinte maneira: 12 relatos de Nova Estratégia, e 19 relatos de Novo Público. Do total de trabalhos relacionados, 17 foram publicados em 2015 e 14 em 2016.

As questões de pesquisa foram elencadas separadamente para cada categoria, visto que o público abordado em cada categoria é diferente. Para os artigos classificados como Nova Estratégia, as seguintes questões de pesquisa foram respondidas: QP1 - Quais foram as estratégias/ferramentas utilizadas?; QP2 - Qual foi o tempo de duração da experiência?; e QP3 - Quais foram as formas de análise empregadas?

QP1 - Quais foram as estratégias/ferramentas utilizadas nestes artigos? As ferramentas e estratégias utilizadas foram bastante diversificadas, porém, observou-se grande incidência de técnicas de gamificação (4). Houve trabalhos que utilizaram mais de uma estratégia/ferramenta. Dentre as utilizadas, estão: exercícios contextualizados em séries e filmes (2), palestra (1), treinamento (1), workshop (1), interdisciplinaridade de matérias (1), podcasts (2), a técnica Coding Dojo (1) e ferramentas como Scratch (2) e Hora do Código (1).

QP2 - Qual foi o tempo de duração das experiências relatadas? Dentre os artigos que apresentaram esta informação, 3 mencionaram ter estendido suas pesquisas durante $o$ semestre letivo, outros artigos compactaram as experiências em: 4 horas (1), entre 12 e 18 horas (3), duas semanas de duração (1), 11 atividades ao longo do projeto (1) e 5 olimpíadas ao longo do projeto (1).

QP3 - Quais foram as formas de análise empregadas? Dentre todas os artigos que mencionaram a técnica de análise aplicada, 3 utilizaram questionários visando obter a percepção dos alunos sobre a estratégia utilizada, 2 analisaram os resultados obtidos pelos alunos nas atividades propostas pela própria pesquisa e 3 artigos mencionaram a aplicação destas duas formas de análise em conjunto. Houve ainda 1 artigo que realizou suas análises baseado na taxa de aprovação dos participantes na disciplina, 1 artigo que analisou apenas a assiduidade dos participantes no projeto e 1 que obteve suas análises confrontando estas duas informações.

De a acordo com os artigos classificados como Novo Público, as seguintes questões de pesquisa foram respondidas: QP4 - Quais foram os públicos alcançados por estas iniciativas?; QP5 - Quais foram os conteúdos de computação ensinados?; QP6 - Quais foram as estratégias ou ferramentas utilizadas?; QP7 - Qual foi o tempo de duração desta experiência?; QP8 - Quais foram as formas de análise empregadas?

QP4 - Quais foram os públicos alcançados por estes trabalhos? Os públicos alvo se mostraram bastante diversificados: alunos do ensino fundamental (8) e alunos do ensino médio (8). As demais iniciativas (3) foram aplicadas em públicos diversificados, ver Quadro 1. Apenas 1 das 19 iniciativas observadas considerou o público da EJA. 
VI Congresso Brasileiro de Informática na Educação (CBIE 2017)

Anais dos Workshops do VI Congresso Brasileiro de Informática na Educação (WCBIE 2017)

Quadro 1 - Público alvo das iniciativas classificadas como Novo Público.

\begin{tabular}{|l|c|l|}
\hline Público Alvo & $\#$ & \multicolumn{1}{|c|}{ Referências } \\
\hline Alunos do ensino fundamental & 8 & $\begin{array}{l}\text { (PAIVA et al., 2015), (LIMA; SOUSA, 2015), (SCHOEFFEL et al., } \\
\text { 2015), (MATTOS et al., 2015), (CASTRO et al., 2016), (SILVA; } \\
\text { SOUZA; SILVA, 2016), (SILVA et al., 2016), (QUEIROZ et al., } \\
\text { 2016) }\end{array}$ \\
\hline Alunos do ensino médio & 8 & $\begin{array}{l}\text { (AURELIANO et al., 2015), (ARANTES et al., 2015), (ZANETTI; } \\
\text { OLIVEIRA, 2015), (LIMA; SOUSA, 2015), (ANDRADE et al., } \\
\text { 2016), (FERREIRA et al., 2016), (VERA et al., 2016), (SOUZA et al., } \\
\text { 2016) }\end{array}$ \\
\hline $\begin{array}{l}\text { Alunos ou professores de cursos } \\
\text { superiores, que não computação. }\end{array}$ & 2 & (KAMPFF et al., 2016), (BARCELOS et al. 2016) \\
\hline $\begin{array}{l}\text { Alunos da educação de jovens e } \\
\text { adultos }\end{array}$ & 1 & (BATHKE; RAABE, 2016) \\
\hline
\end{tabular}

QP5 - Quais foram os conteúdos de computação ensinados? O conteúdo mais presente foi programação, mencionado em 17 artigos. Em segundo lugar, raciocínio lógico, mencionado em 8 artigos, seguido de robótica, mencionado em 6 artigos e algoritmos, mencionado em 5 artigos.

Vale ressaltar que as pesquisas podem citar um ou mais conteúdos trabalhados, pois nem sempre a introdução de um assunto resultará obrigatoriamente na introdução de outro (e.g., é possível ensinar algoritmos a um aluno sem ensiná-lo a programar, porém para que ele possa programar é esperado que ele saiba o que é um algoritmo).

QP6 - Quais foram as estratégias/ferramentas utilizadas nas pesquisas? Foram várias, sendo Scratch a mais citada (9). As demais ferramentas podem ser observadas no Quadro 2.

Quadro 2 - Ferramentas ou estratégias utilizadas nas pesquisas Novo Público.

\begin{tabular}{|l|l|l|}
\hline Ferramentas/estratégias & $\#$ & \multicolumn{1}{|c|}{ Referências } \\
\hline Scratch & 9 & $\begin{array}{l}\text { (AURELIANO et al., 2015), (ARANTES et al., 2015), (SCHOEFFEL et } \\
\text { al., 2015), (SILVA; SOUZA; SILVA, 2016), (ANDRADE et al., 2016), } \\
\text { (FERREIRA et al., 2016), (VERA et al., 2016), (BARCELOS et al., } \\
\text { 2016), (BATHKE; RAABE,2016) }\end{array}$ \\
\hline $\begin{array}{l}\text { LEGO (kit Mindstorm \& } \\
\text { Educação Tecnológica) }\end{array}$ & 4 & $\begin{array}{l}\text { (SCHOEFFEL et al., 2015), (MATTOS et al., 2015), (SILVA et al., } \\
\text { 2016), (SOUZA et al., 2016). }\end{array}$ \\
\hline Computação Desplugada & 2 & (PAIVA et al., 2015), (FERREIRA et al., 2016) \\
\hline IDE Portugol & 2 & (LIMA; SOUSA, 2015), (LIMA; SOUSA, 2015) \\
\hline Scratch 4 Arduíno & 1 & (ZANETTI; OLIVEIRA, 2015) \\
\hline Gamificação & 2 & (SCHOEFFEL et al., 2015), (ANDRADE et al., 2016) \\
\hline
\end{tabular}


VI Congresso Brasileiro de Informática na Educação (CBIE 2017)

Anais dos Workshops do VI Congresso Brasileiro de Informática na Educação (WCBIE 2017)

\begin{tabular}{|l|c|l|}
\hline RoboMind & 1 & (SCHOEFFEL et al., 2015) \\
\hline Code.org & 2 & (CASTRO et al., 2016), (BATHKE; RAABE, 2016) \\
\hline VisuAlg & 2 & (FERREIRA et al., 2016), (VERA et al., 2016) \\
\hline Curso Online & 1 & (BARCELOS et al., 2016) \\
\hline $\begin{array}{l}\text { DuinoBlocks4Kids + Materiais } \\
\text { de robótica }\end{array}$ & 1 & (QUEIROZ et al., 2016) \\
\hline $\begin{array}{l}\text { Canvas algorítmico } \\
\begin{array}{l}\text { Conceitos de computação em } \\
\text { outras matérias (música, } \\
\text { biologia, etc.) }\end{array}\end{array}$ & 2 & (PAIVA et al., 2015), (VERA et al., 2016) \\
\hline
\end{tabular}

QP7 - Qual foi o tempo de duração das pesquisas relatadas? Houve grande diversidade entre as durações observadas em cada pesquisa. Dentre o total, 4 pesquisas tiveram duração entre 4 e 12 horas, 6 pesquisas tiveram duração entre 12 e 30 horas, 2 pesquisas tiveram duração entre 40 e 48 horas de aula. Ainda, houve 2 pesquisas com duração de 6 encontros, 1 pesquisa com duração de 8 encontros, e 1 última pesquisa com duração de 10 módulos, conduzida no estilo de curso online.

QP8 - Quais foram as formas de análise empregadas? 12 pesquisas optaram pela aplicação de questionários, com o objetivo de obter a opinião dos participantes sobre as estratégias aplicadas. Houve 4 pesquisas que aplicaram pré e pós testes, a fim de confrontá-los para analisar o progresso dos alunos; outras 5 pesquisas que optaram por avaliar os artefatos finais produzidos pelos alunos; e 1 pesquisa que analisou os resultados obtidos pelos participantes em atividades externas à pesquisa (participação em olimpíada).

\section{Desafios e Oportunidades de uma pesquisa envolvendo a EJA}

Diante do panorama exposto, é preciso considerar que uma proposta de pesquisa neste público precisará enfrentar diferentes desafios e oportunidades para que efetivamente faça sentido para seus participantes.

EJA versus tecnologia. Uma característica comum do público da EJA é a presença de diversos contextos econômicos, sociais e culturais dentre os alunos. A falta de vivência com a tecnologia costuma ser bastante observada neste público, sendo, portanto, uma área de conhecimento não dominada por eles. Desta forma, desenvolver um projeto de ensino de fundamentos computacionais visando a construção do pensamento computacional neste público é um desafio.

EJA \& tecnologia. Por outro lado, promover a aproximação dos alunos da EJA com a tecnologia pode se apresentar como uma oportunidade para se prepararem para interagir com a sociedade, atualmente permeada por tecnologias de informação e comunicação. Pode ser, até mesmo, uma oportunidade para crescimento profissional. 
Conhecimento não se ensina, se constrói. Do ponto de vista pedagógico, de acordo com Paulo Freire (1996, p.24) "ensinar não é transferir conhecimento, mas criar possibilidades para a sua produção ou a sua construção", portanto, este parece um objetivo de pesquisa promissor: criar possibilidades para a construção de entendimento sobre o pensamento computacional, de forma individual e socialmente compartilhada, levando em consideração as particularidades deste público.

Não fazer "para", fazer "com". O desenvolvimento prévio das atividades pelos pesquisadores tende a seguir um caminho semelhante ao conceituado como "educação bancária" (FREIRE, 1968), que se caracteriza pela imposição do conhecimento realizada pelo professor sobre o aluno. Especialmente levando em consideração as características deste público, é preciso adotar outra perspectiva, pensando, projetando, conduzindo e avaliando atividades com a participação das diferentes partes interessadas envolvidas.

Não esquecer o mundo lá fora. Freire indaga (1996, p.32): "Por que não discutir com os alunos a realidade concreta a que se deva associar a disciplina cujo conteúdo se ensina? [...] por que não estabelecer uma "intimidade" entre os saberes curriculares fundamentais aos alunos e a experiência social que eles têm como indivíduos?".

É necessário atentar para a integração que precisa existir entre os conteúdos lecionados e o ambiente sociocultural ao qual o aluno da EJA está inserido. Por meio de práticas participativas torna-se possível abordar este desafio, conhecendo melhor a realidade dos alunos, da escola e da comunidade, e envolvendo os saberes previamente obtidos por eles. Então, professor e alunos juntos desenvolvem atividades, trazendo principalmente as dúvidas e vivências dos mesmos para serem trabalhadas.

\section{Considerações}

O pensamento computacional auxilia na compreensão e resolução de diversos problemas, relacionados ou não com a computação. Embora muitas pesquisas estejam sendo feitas nesta área no Brasil, o mapeamento apresentado neste artigo mostra que essas pesquisas não têm contemplado o público da educação de jovens e adultos. Esse público possui a necessidade de se atualizar em diversos contextos da sociedade moderna. É um público que, geralmente, precisa trabalhar para o sustento de sua casa e família e, por meio dos estudos, busca obter uma melhor posição social.

Por ser um público que possui características diferenciadas e contextos socioculturais diferenciados, o desenvolvimento de uma pesquisa neste público revela muitos desafios, demandando a elaboração de estratégias para cumprir o objetivo proposto. $\mathrm{O}$ desenvolvimento do pensamento computacional neste público significa, além de aquisição de conhecimento e habilidades, uma chance de se atualizar sobre os recursos tecnológicos disponíveis, tornando os alunos mais preparados para lidar com eles, preparando-os para uma sociedade mediada por tecnologia.

Este artigo apresentou uma discussão sobre o desenvolvimento do pensamento computacional no ensino de jovens e adultos com o intuito de sensibilizar para a importância de se investigar, propor e experimentar formas de criar possibilidades para a 
VI Congresso Brasileiro de Informática na Educação (CBIE 2017)

Anais dos Workshops do VI Congresso Brasileiro de Informática na Educação (WCBIE 2017)

construção do pensamento computacional, expondo também desafios e oportunidades oriundas das limitações e particularidades deste público.

\section{Referências}

ANDRADE, R. et al. Uma Proposta de Oficina de Desenvolvimento de Jogos Digitais para Ensino de Programação. Anais dos Workshops do Congresso Brasileiro de Informática na Educação, v. 5, n. 1, p. 1127, 2016.

ARANTES, F. et al. Uma dinâmica para ensino de conceitos fundamentais de programação. Anais dos Workshops do Congresso Brasileiro de Informática na Educação, v. 4, n. 1, p. 1218, 2015.

AURELIANO, V. et al. Aprendendo linguagem de programação através da auto-explicação de exemplos em vídeo. Anais dos Workshops do Congresso Brasileiro de Informática na Educação, v. 4, n. 1, p. 1359, 2015.

BARANAUSKAS, M. C. C.; CARBAJAL, M. L. The Social Nature of Programming: Children and Fluency. Internacional Conference on Human Interaction, p. 291-308, 2017.

BARCELOS, T. et al. Formação online para o desenvolvimento do Pensamento Computacional em professores de Matemática. Anais dos Workshops do Congresso Brasileiro de Informática na Educação, v. 5, n. 1, p. 1228, 2016.

BARR, V.; STEPHENSON, C. Computational thinking to k-12: What is involved and what is the role of the computer science education community. ACM Inroads, v. 2, n. 1, p. 4854, 2011.

BATHKE, J.; RAABE, A. Pensamento Computacional na Educação de Jovens e Adultos: Lições Aprendidas. Anais dos Workshops do Congresso Brasileiro de Informática na Educação, v. 5, n. 1, p. 1087, 2016.

CASTRO, M. et al. Ensino de Matemática Através de Algoritmos Utilizando Jogos para Alunos do Ensino Fundamental II. Anais dos Workshops do Congresso Brasileiro de Informática na Educação, v. 5, n. 1, p. 1039, 2016.

FERREIRA, A. C. et al. Hello World: relato de experiência de um curso de iniciação à programação. Anais dos Workshops do Congresso Brasileiro de Informática na Educação, v. 5, n. 1, p. 1306, 2016.

FREIRE, Paulo. (1996) Pedagogia da autonomia: saberes necessários à prática educativa. Editora Paz e Terra. São Paulo.

KAMPFF, A. J. C. et al. Pensamento Computacional no Ensino Superior: Relato de uma oficina com professores da Universidade do Vale do Rio dos Sinos. Anais dos Workshops do Congresso Brasileiro de Informática na Educação, v. 5, n. 1, p. 1316, 2016.

LIMA, Á. C.; SOUSA, D. F. DE. Desenvolvimento do Raciocínio Lógico e Algoritmo Através do Programa Institucional de Bolsas de Iniciação à Docência no Ensino Fundamental. Anais dos Workshops do Congresso Brasileiro de Informática na Educação, v. 4, n. 1, p. 1379, 2015.

MATTOS, S. D. G. et al. Introdução à Robótica e Estímulo à Lógica de Programação no Ensino Básico Utilizando o Kit Educativo LEGO ${ }^{\circledR}$ Mindstorms. Anais dos Workshops do Congresso Brasileiro de Informática na Educação, v. 4, n. 1, p. 1418, 2015. 
VI Congresso Brasileiro de Informática na Educação (CBIE 2017)

Anais dos Workshops do VI Congresso Brasileiro de Informática na Educação (WCBIE 2017)

NATIONAL RESEARCH COUNCIL. 2010. Report of a Workshop on the Scope and Nature of Computational Thinking. Washington, DC: The National Academies Press. https://doi.org/10.17226/12840

NERI, M. Motivos da evasão escolar. Brasília: Fundação Getulio Vargas, p. 1-34, 2009.

PAIVA, L. F. DE et al. Uma Experiência Piloto de Integração Curricular do Raciocínio Computacional na Educação Básica. Anais dos Workshops do Congresso Brasileiro de Informática na Educação, v. 4, n. 1, p. 1300, 2015.

QUEIROZ, R.et al. DuinoBlocks4Kids: Ensinando conceitos básicos de programação a crianças do Ensino Fundamental I por meio da Robótica Educacional. Anais dos Workshops do Congresso Brasileiro de Informática na Educação, v. 5, n. 1, p. 1169, 2016.

SCHOEFFEL, P. et al. Uma Experiência no Ensino de Pensamento Computacional para Alunos do Ensino Fundamental. Anais dos Workshops do Congresso Brasileiro de Informática na Educação, v. 4, n. 1, p. 1474, 2015.

SILVA, D. P. DA et al. Aplicação de Robótica na Educação de Forma Gradual para o Estímulo do Pensamento Computacional. Anais dos Workshops do Congresso Brasileiro de Informática na Educação, v. 5, n. 1, p. 1188, 2016.

SILVA, G. T. DA; SOUZA, J. L. DE; SILVA, L. A. M. DA. Aplicação da Ferramenta Scratch para o Aprendizado de Programação no Ensino Fundamental I. Anais dos Workshops do Congresso Brasileiro de Informática na Educação, v. 5, n. 1, p. 1285, 2016.

SOUZA, I. M. L. DE. et al. Introdução do Pensamento Computacional na Formação Docente para Ensino de Robótica Educacional. Anais dos Workshops do Congresso Brasileiro de Informática na Educação, v. 5, n. 1, p. 1265, 2016.

VAZ, C. A. Google Marketing. The effects of brief mindfulness intervention on acute pain experience: An examination of individual difference, v. 2o edição, p. 19-459, 2015.

VERA, W. F. M. et al. Dó, Ré, Mergesort: um relato de experiência interdisciplinar de ensino de computação com matemática e música. Anais dos Workshops do Congresso Brasileiro de Informática na Educação, v. 5, n. 1, p. 1275, 2016.

WING, J. Computational Thinking. Communications of the ACM; v.49, v. 3, p. 33-35, 2006.

ZANETTI, H.; OLIVEIRA, C. Práticas de ensino de Programação de Computadores com Robótica Pedagógica e aplicação de Pensamento Computacional. Anais dos Workshops do Congresso Brasileiro de Informática na Educação, v. 4, n. 1, p. 1236, 2015.

ZORZO, A. F. et al. Referenciais de Formação em Computação: Educação Básica. n. 1, p. $1-9,2017$. 